\title{
A EDUCAÇÃO A DISTÂNCIA (EAD) COMO ALTERNATIVA PARA LEVAR O CONHECIMENTO ÀS COMUNIDADES RURAIS
}

\author{
Geisiane dos Santos Araújo, Maria Eliza Nigro Jorge \\ Universidade do Oeste Paulista, Mestrado em Meio Ambiente e Desenvolvimento Regional (MMADRE), Presidente \\ Prudente, SP. E-mail: geisisantos2@gmail.com.
}

\begin{abstract}
RESUMO
Para que de fato um país possa experimentar o desenvolvimento, é fundamental a realização de acentuados investimentos em Educação, em especial no que se refere à educação dos povos do campo, onde o desafio apresenta-se mais intenso. Neste sentido, buscou-se compreender a Educação a Distância - EaD como alternativa para levar o conhecimento às comunidades rurais, numa tentativa de contribuir por um mundo mais justo, humano e de oportunidades à toda sociedade. Realizou-se uma reflexão sobre a realidade da educação ofertada, as oportunidades de acesso à educação proporcionada às comunidades rurais, bem como seus dilemas. O método adotado para desenvolvimento deste artigo foi um estudo teórico, com pesquisa bibliográfica de caráter dedutiva e qualitativa, amparada pelas análises realizadas por renomados autores e pela Associação Brasileira de Educação a Distância (ABED). Em sua vertente aplicada, o estudo se fez documental ao utilizar a técnica de observação direta extensiva, ou seja, a visita e observação para coleta de informações em escolas de assentamentos rurais.
\end{abstract}

Palavras-chave: Desenvolvimento, Investimentos, Educação a Distância, Conhecimento, Comunidades Rurais.

\section{THE DISTANCE EDUCATION AS AN ALTERNATIVE TO TAKE KNOWLEDGE TO RURAL COMMUNITIES}

\begin{abstract}
For a country to truly experience the development, it is critical to conduct investments in education, especially when it comes to the education of people from the field, where the challenge has become more intense. In this means, we understood the Distance Education as an alternative to bring knowledge to rural communities in an attempt to contribute to a more fare, humane world and opportunities to the whole society. There was consideration on the reality of the education offered, the opportunities of accessing the education provided to rural communities and their dilemmas. The method adopted for the development of this article was a theoretical study with literature of deductive and qualitative character, supported by analyzes by renowned authors and the Brazilian Association of Distance Education (BADE). In its applied aspect, the study became documental by using the extensive direct observation technique, being the visit and observation to collect information on schools in rural settlements.
\end{abstract}

Keywords: Development, Investiments, Distance Education, Knowledge, Rural communities. 


\section{INTRODUÇÃO}

A educação é reconhecida como o caminho pelo qual passa o desenvolvimento, em especial quando se pensa neste de maneira sustentável. Mas, para que isso ocorra, não bastam apenas investimentos pontuais em educação, quando esta direciona-se apenas a uma parcela da população. Os países que experimentaram o desenvolvimento realizaram grandes investimentos e, em longo prazo, tornando um compromisso inegociável no âmbito eleitoral, e o fizeram para proporcionar educação à toda sociedade.

No entanto, levar educação ao meio rural é um grande desafio, desde os tempos em que algumas escolas foram inseridas em áreas rurais onde havia um determinado adensamento populacional que justificasse a sua instalação. Quando se pensa em uma educação de qualidade, conteúdos atualizados e utilize mecanismos e ferramentas modernas, o desafio se apresenta mais intenso. É emergencial que se pense em alternativas capazes de proporcionar uma inclusão educacional ao maior contingente de pessoas possível, em especial daquelas que residem na zona rural. Dessa forma, a Educação a Distância, referenciada pela sigla EaD, apresenta-se como uma alternativa que merece ser apreciada com atenção.

Sendo assim, há interesse dos sujeitos envolvidos (governos, movimentos sociais, ONG's e comunidades rurais) na manutenção de uma estrutura educacional no campo? A Educação a Distância é considerada, pelas partes interessadas, uma alternativa viável para levar conhecimento às comunidades rurais? Existe infraestrutura suficiente e ativa propícia para a modalidade EaD?

O objetivo deste trabalho consiste em elucidar as questões elencadas e validar a hipótese considerada, através de uma reflexão sobre a Educação a Distância (EaD) como alternativa para levar o conhecimento às comunidades rurais. Com a finalidade de identificar as oportunidades de acesso à educação proporcionadas, foi realizada uma análise sobre a realidade da educação oferecida junto às comunidades rurais.

O desenvolvimento deste trabalho deu-se através de um estudo teórico, com pesquisa bibliográfica de caráter dedutiva e qualitativa. Em sua vertente aplicada, o estudo se fez documental ao utilizar a técnica de observação direta extensiva, ou seja, a visita e observação para coleta de informações em escolas de assentamentos rurais localizados no município de Bataguassu/MS.

\section{UM BREVE HISTÓRICO DA EDUCAÇÃO NO CAMPO}

No passado oferecia-se, no campo, apenas o ensino primário, hoje denominado 1ำ ciclo da educação de base. Quando não havia um contingente de alunos que justificasse a abertura de uma 
sala para cada série, abria-se uma sala mista e cabia ao docente o desafio de lecionar conteúdos distintos, a públicos diferentes que ocupavam o mesmo espaço físico. "A instalação das escolas multisseriadas do ensino primário traduz a precariedade da escolarização oferecida pelo poder público aos jovens camponeses" (SKRZYPCZAK \& SCHLOSSER, 2014, p. 142-143).

Para obter acesso à educação básica, as crianças oriundas das propriedades rurais têm no máximo duas alternativas: frequentam a escola na cidade mais próxima ou, se existir, podem optar por frequentar a escola rural na região onde moram. Com o passar do tempo e o esvaziamento do campo, promovido pelo processo de urbanização e industrialização, grande parte dessas escolas rurais, em algumas regiões a sua totalidade, tornam-se inviáveis e são fechadas. Assim, não resta outra alternativa àqueles que permanecem na zona rural senão recorrer a escola da cidade mais próxima, com a utilização de seus próprios meios e recursos. É possível observar com isso, um aumento no isolamento e na complexidade para que as comunidades rurais tenham acesso à educação. Apesar da existência de escolas no campo ser uma realidade no Brasil, havendo uma drástica redução decorrente do processo de urbanização, segundo Oliveira e Dalmagro (2014) é somente a partir da década de 90 do século XX que os projetos relacionados a Educação do Campo passam a fazer parte da pauta dos movimentos sociais e da academia.

Ocorre que, não é interessante para a classe dominante a conscientização dos povos do campo e um ensino voltado às necessidades, interesses e realidade desses. Muito pelo contrário, quanto mais desinformados sobre seus direitos forem, aumenta a possibilidade de subordinação pelo capital.

\section{A EDUCAÇÃO A DISTÂNCIA (EaD)}

A Educação a Distância é uma modalidade de ensino e estudo que existe há um muito tempo no Brasil e o seu crescimento tem se demonstrado bastante expressivo nos últimos tempos. Esse crescimento tem sido sustentado pelo desenvolvimento de novas tecnologias, em especial as Tecnologias da Informação e Comunicação (TICs). A legislação brasileira, através do Decreto no 5.622/2005, em seu artigo 1으, estabelece

[...] a educação a distância como modalidade educacional na qual a mediação didático-pedagógica nos processos de ensino-aprendizagem ocorre com a utilização de meios e tecnologias de informação e comunicação, com estudantes e professores desenvolvendo atividades educativas em lugares e tempos diversos (BRASIL, 2005). 
É importante salientar que este decreto tem por finalidade regulamentar o artigo no 80 da Lei no 9.394/1996, a Lei de Diretrizes e Bases da Educação Nacional (LDB). Na mesma linha deste dispositivo legal, para a ABED (2014) uma EaD é

[...] entendida como a modalidade educacional em que as atividades de ensino-aprendizagem são desenvolvidas majoritariamente (e, em bom número de casos, exclusivamente) sem que alunos e professores estejam presentes no mesmo lugar, na mesma hora (ABED, 2014, p. 19).

Existe, portanto, uma diversidade de formas para conceber a Educação a Distância, que vão desde a oferta de formações consorciadas, ou seja, parte a distância e parte presencial, havendo a predominância da primeira, indo até cursos ofertados totalmente online. A tecnologia vem então como uma ferramenta capaz de alavancar a educação em regiões periféricas, atuando como um agente catalizador do desenvolvimento humano social. Por isso, um programa ou projeto de EaD deve ser flexível e estar focado no aluno, bem como no ambiente em que vive e interage. No entanto, a implementação e uso dessas tecnologias requer uma ruptura com os modelos e práticas educacionais até então vigentes, conforme destaca Lévy (2005).

Não se trata aqui de utilizar as tecnologias a qualquer custo, mas sim de acompanhar consciente e deliberadamente uma mudança de civilização que questiona profundamente as formas institucionais, as mentalidades e a cultura dos sistemas educacionais tradicionais e, sobretudo, os papeis de professor e de aluno (LÉVY, 2005, p. 172).

Portanto, não trata-se de utilizar a tecnologia por mero modismo, nem de simplesmente acompanhar uma tendência, mas sim de moldar-se a uma realidade já consolidada. Busca-se usufruir dessas tecnologias de forma a gerar maior produtividade nos processos educacionais e maior comodidade aos sujeitos envolvidos. Além da evasão, constituem obstáculos a serem superados na implementação da EaD "os desafios organizacionais da migração de presencial para distância, a resistência dos alunos e a resistência dos professores" (ABED, 2014, p. 22). No entanto, trata-se de um processo ainda não concluído e que talvez nunca o chegue a ser, pois as inovações fazem parte do ciclo evolutivo da própria humanidade. Assim,

O século XXI inicia-se sob o signo da transição na educação. A importância cada vez maior das tecnologias e das ciências; a substituição dos livros por outras formas de transmissão de conteúdos (como a informação digitalizada, as imagens e os sons etc.); o desenvolvimento das linguagens de computador e da própria informática; enfim, todas as consequências da revolução da informação exigem alterações profundas nos processos educacionais e nas teorias pedagógicas. E a Educação a distância, nesse sentido, tem ditado as regras para a educação do futuro (MAIA \& MATTAR, 2007, p. 3). 
A Educação a Distância deve propiciar condições mais favoráveis para uma efetiva aprendizagem pelo discente, em dias, horários e ritmos customizados às particularidades de cada um. Pois, a jornada de trabalho no campo costuma começar muito cedo, antes mesmo do sol nascer, com os processos de ordenha e alimentação dos animais por exemplo. É uma rotina árdua e que envolve os sete dias da semana. A EaD pensada ao nível da população rural deve contemplar, além da flexibilidade para se realizar as atividades inerentes a qualquer hora, deve ser dotada de componentes curriculares próximos de sua realidade, que os ajude a resolver seus dilemas diários.

O Censo da EaD, realizado pela ABED (2014) aponta que desde 2010, a exceção de alguns casos muito específicos, predomina aluno do sexo feminino e com certa maturidade, predominância de alunos entre 31 e 40 anos, conforme demonstra a Tabela 1. A Tabela 2, por sua vez, associa o perfil ocupacional dos educandos com a modalidade de EaD procurada.

Tabela 1. Perfil etário dos educandos dos cursos EaD oferecidos pelas instituições formadoras participantes do Censo EaD.BR 2013.

\begin{tabular}{|c|c|c|c|c|c|}
\hline \multirow{2}{*}{\multicolumn{2}{|c|}{ Cursos }} & \multicolumn{4}{|c|}{ Idade Média dos Educandos } \\
\hline & & $\begin{array}{l}\text { Menor de } \\
20 \text { anos }\end{array}$ & $\begin{array}{c}\text { Entre } 21 \text { e } \\
30 \text { anos }\end{array}$ & $\begin{array}{c}\text { Entre } 31 \text { e } \\
40 \text { anos }\end{array}$ & $\begin{array}{c}\text { Maior de } \\
41 \text { anos }\end{array}$ \\
\hline \multicolumn{2}{|c|}{ Regulamentado totalmente a distância } & 2 & 41 & 77 & 9 \\
\hline \multicolumn{2}{|c|}{ Regulamentado semipresencial } & 4 & 30 & 33 & 1 \\
\hline \multicolumn{2}{|c|}{ Disciplina(s) EaD } & 6 & 55 & 20 & 0 \\
\hline \multirow{2}{*}{ Livre } & Não corporativo & 7 & 34 & 45 & 1 \\
\hline & Corporativo & 0 & 19 & 47 & 8 \\
\hline \multicolumn{2}{|r|}{ Total } & 7 & 53 & 92 & 9 \\
\hline
\end{tabular}

Fonte: $\operatorname{ABED}(2014$, p. 23). Org. Geisiane dos Santos Araújo

Tabela 2. Perfil ocupacional dos educandos dos cursos EaD das instituições participantes do Censo EAD.BR 2013 segundo tipo e nível de curso.

\begin{tabular}{|c|c|c|c|c|c|}
\hline \multirow[b]{2}{*}{ Cursos } & \multirow[b]{2}{*}{ Nível } & \multicolumn{3}{|c|}{ Quantidade de Respostas } & \multirow[b]{2}{*}{ Total } \\
\hline & & $\begin{array}{l}\text { Somente } \\
\text { estuda }\end{array}$ & $\begin{array}{l}\text { Estuda e } \\
\text { trabalha }\end{array}$ & $\begin{array}{l}\text { Estuda e está } \\
\text { desempregado }\end{array}$ & \\
\hline \multirow{5}{*}{$\begin{array}{l}\text { Regulamentado } \\
\text { totalmente a } \\
\text { distância }\end{array}$} & EJA & 5 & 11 & 0 & 16 \\
\hline & Ensino profissionalizante & 2 & 26 & 0 & 28 \\
\hline & Superior graduação & 0 & 41 & 1 & 42 \\
\hline & Superior pós-graduação & 0 & 41 & 0 & 41 \\
\hline & $\begin{array}{l}\text { Disciplina obrigatória em } \\
\text { qualquer nível }\end{array}$ & 0 & 2 & 0 & 2 \\
\hline \multicolumn{2}{|r|}{ Total } & 7 & 121 & 1 & 129 \\
\hline
\end{tabular}

Fonte: $\operatorname{ABED}(2014$, p. 23). Org. Geisiane dos Santos Araújo 
A tabela 2 permite visualizar que a clientela que procura a EaD já atua profissionalmente e se concentra nos cursos de graduação e pós graduação. No entanto, merece destaque o fato de que $12,40 \%$ dos entrevistados frequentam curso de Educação de Jovens e Adultos (EJA), o que reflete a existência de uma parcela da população em atraso escolar. Ao se considerar que há um envelhecimento da população rural, em especial nos assentamentos rurais, pois os jovens estão migrando do campo para a cidade em busca de melhores condições de vida e sobrevivência, é possível especular que esta seja uma modalidade que poderia ter uma considerável aplicabilidade nestas localidades. Segundo Godoy (2007, p. 24), "o desenvolvimento integral das populações assentadas depende da capacidade de garantir o acesso aos diversos direitos sociais, como a educação". Diminuindo assim, a evasão camponesa.

\section{UMA AMOSTRA DE ASSENTAMENTOS DO MATO GROSSO DO SUL}

Na busca por sair do campo teórico e conhecer a realidade, foram realizadas incursões em dois Projetos de Assentamento (PA's), localizados no município de Bataguassu/MS, os quais serão denominados de A e B. Estas incursões tiveram o fito de averiguar ali a existência de escola, do tipo de escola e de formação oferecida, a oferta de componentes curriculares específicos à realidade local, a existência de sala de informática e infraestrutura para EaD, bem como a existência de casos de EaD.

O Projeto de Assentamento A foi implantado em 1998 para beneficiar 70 famílias. Na sede do assentamento funcionou, por pouco tempo, uma escola, mas pela proximidade com o município encerrou precocemente suas atividades. Sua associação conquistou, após muita luta, duas salas de informática, oriundas de programas governamentais diferentes. Uma dessas salas, a mais antiga, é bastante utilizada pela comunidade assentada, o que foi possível constatar pela utilização em trabalhos escolares e até mesmo profissionais. Possui 10 (dez) equipamentos em ótimo estado de conservação e relativamente modernos, 2 (dois) multifuncionais e 1 (um) projetor multimídia.

Esta sala funciona de segunda a sexta-feira no período da manhã, tarde e noite, e, conta com 1 monitora para auxiliar as pessoas que possuem dificuldade para manusear os computadores. Nos dias e horários em que a sala não funciona, caso seja necessário, o interessado pode pegar a chave da sala com a pessoa responsável, utilizar e devolver ao final. Segundo relatos, várias pessoas utilizam o espaço para assistir aulas e/ou realizar cursos a distância. Pela flexibilidade no acesso à educação devido a existência dessa sala, visto que, tem contribuído significativamente na permanência dos jovens no campo, então a associação deste PA resolveu 
candidatar-se para receber uma segunda sala. A associação foi contemplada e a segunda sala já foi montada. No entanto, ainda não está em operação porque aguarda a instalação da antena para acesso à internet.

No Projeto de Assentamento B, implantado em 1994 para beneficiar 156 famílias, existe uma escola que atende, pelo município, no período vespertino, a alunos do 1으 ao 9 o ano do Ensino Fundamental. No período noturno a escola atende, via estado, aos discentes de 1ㅇ ao 3으 ano do Ensino Médio, sendo que o 10 e 2 o anos estão agrupados em uma sala multisseriada, caracterizando a precariedade atual na educação ofertada na zona rural. Em relatos, essa escola apresenta duas características que Ihe são peculiares: a) é considerada uma "escola do campo"; e b) é a única escola de assentamento no município que proporciona o Ensino Médio. No que se refere a primeira destas características, Caldart (2003) enfatiza:

Uma escola do campo não é, afinal, um tipo diferente de escola, mas sim é a escola reconhecendo e ajudando a fortalecer os povos do campo como sujeitos sociais, que também podem ajudar no processo de humanização do conjunto da sociedade, com suas lutas, sua história, seu trabalho, seus saberes, sua cultura, seu jeito. Também pelos desafios da sua relação com o conjunto da sociedade. Se é assim, ajudar a construir escolas do campo é, fundamentalmente, ajudar a constituir os povos do campo como sujeitos, organizados e em movimento. Porque não há escolas do campo sem a formação dos sujeitos sociais do campo, que assumem e lutam por esta identidade e por um projeto de futuro (CALDART, 2003, p. 66. Grifos no original).

A escola existente no PA B é denominada Escola do Campo, por possuir em seus componentes curriculares três disciplinas específicas do campo, quais sejam: Indústrias Rurais, Zootecnia e Terra, Vida e Trabalho. No entanto, essas disciplinas são, por vezes, ministradas por docentes que não possuem suficiente familiaridade com a realidade do campo, produzindo certa rejeição pelos discentes. Muitos alegam possuir mais conhecimento no assunto do que seus professores. Diante desta realidade, pode-se afirmar que essa escola não se concretiza, na prática, como "do campo", bem como há descaso político referente a qualidade do ensino ali desenvolvido.

Nesta escola existe um laboratório de informática com acesso à internet. Porém, nem todos os equipamentos encontram-se em condições plenas de uso e, além do mais, quando vários equipamentos estão em uso e conectados à internet, a navegação torna-se relativamente precária, o que impossibilita a realização de estudos e pesquisas. Isso denota que, apesar da existência do espaço e dos equipamentos, a infraestrutura existente deixa a desejar. 
Em função disso, os assentados realizaram investimentos próprios para fazer com que o laboratório de informática possa operar nas condições necessárias, e, assim poderem realizar cursos a distância. A sala está em funcionamento e conta com um monitor remunerado pelo município. Muitos dos assentados deste PA optam por realizar cursos na modalidade EaD devido a distância do PA para a cidade, o que um tempo, na zona rural difícil de dispor, e, também pela falta de transporte. Eles acreditam que esta modalidade de ensino é a melhor de todos os tempos, pois assim, não precisam deixar suas propriedades para dar continuidade nos estudos indo para a cidade. Essa é a importância da EaD para as comunidades rurais.

\section{CONSIDERAÇÕES FINAIS}

As compreensões realizadas neste trabalho, permitem afirmar que a Educação a Distância é uma alternativa viável para levar o conhecimento às comunidades camponesas. No entanto, há um grande caminho a ser percorrido até que isso torne-se realidade geral. Não se pode negar a parcial ou total inexistência de infraestrutura adequada para esta finalidade, bem como a sua relativa inadequação quando existe, pois para constatar basta uma rápida visita a um dos tantos assentamentos de reforma agrária existentes no Brasil.

Apesar dos avanços apresentados pelas Tecnologias da Informação e Comunicação (TIC's), constata-se que os seus benefícios permanecem, na maioria dos casos, restritos ao espaço urbano e a uma parcela privilegiada da sociedade. No entanto, as ações engendradas pelo Brasil neste sentido têm se demonstrado mínimas e de baixo índice de efetividade.

A ausência ou o baixo índice da presença de Educação a Distância encontrada na realidade rural brasileira demonstra a baixa priorização, em todos os sentidos, que os sucessivos governos têm dado às necessidades da massa camponesa, em especial à educação no campo. As salas multisseriadas, os problemas de transporte, o fechamento de escolas, a falta de infraestrutura e, por fim, a ausência de componentes curriculares específicos para o meio rural demonstram a falta de interesse dos governantes em promover, de fato, uma educação de qualidade no campo. Pelo contrário, cooptado pelo capital o Estado empreende todos os esforços necessários para deslocar os jovens do campo para a cidade e lhes ofertar uma educação que vai de encontro aos interesses do capital. Isso coloca em risco a sustentabilidade e o futuro das pequenas propriedades e dos próprios projetos de assentamentos de reforma agrária. 


\section{REFERÊNCIAS}

ABED, Associação Brasileira de Educação a Distância. Censo EAD.BR: relatório analítico da aprendizagem a distância no Brasil 2013. 1a ed. Curitiba: IBPEX, 2014. Disponível em: <http://www.abed.org.br/censoead2013/CENSO_EAD_2013_PORTUGUES.pdf>. Acesso em: 26 de fev. 2015.

BRASIL. Decreto no 5.622, de 19 de dezembro de 2005. Regulamenta o art. 80 da Lei no 9.394, de 20 de dezembro de 1996, que estabelece as diretrizes e bases da educação nacional. Brasília, Dezembro de 2005. Disponível em: <http://portal.mec.gov.br/seed/arquivos/pdf/dec_5622.pdf>. Acesso em: 26 de fev. 2015.

CALDART, Roseli S. A Escola do Campo em Movimento. Currículo sem Fronteiras, v. 3, no 1, p. 6081, Jan/Jun 2003. Disponível em: <http://www.ia.ufrrj.br/ppgea/conteudo/conteudo-20091/Educacao-MII/3SF/A_ESCOLA_DO_CAMPO_EM_MOVIMENTO.pdf>. Acesso em 24 de jan. 2015.

GODOY, Nara. A Era Digital Chega aos Assentamentos. Revista Fatos da Terra, no 19, 2007. Disponível em: <http://www.itesp.sp.gov.br/br/info/publicacoes/arquivos/FatosTerra19.pdf>. Acesso em: 22 de jul. 2014.

LÉVY, Pierre. Cibercultura. São Paulo: Editora 34, 2005.

MAIA, Carmem; MATTAR, João. ABC da EaD: a educação a distância hoje. 1a ed. São Paulo: Pearson Prentice Hall, 2007.

OLIVEIRA, Marcos A. de; DALMAGRO, Sandra L. A Questão Agrária, a Educação do Campo e os Projetos em Disputa. Revista Reflexão e Ação, v. 22, n. 2, p. 94-119. Santa Cruz do Sul. Jul./Dez. 2014.

SKRZYPCZAK, Valdir; SCHLOSSER, Marli T. S. (Des)Qualificação dos Trabalhadores Frente ao Capital Agroindustrial, na Cidade de Xaxim - SC. Revista P. 